\title{
Subtelomere specific microarray based comparative genomic hybridisation: a rapid detection system for cryptic rearrangements in idiopathic mental retardation
}

\author{
N Harada, E Hatchwell, N Okamoto, M Tsukahara, K Kurosawa, H Kawame, T Kondoh, \\ H Ohashi, R Tsukino, Y Kondoh, O Shimokawa, T Ída, T Nagai, Y Fukushima, K Yoshiura, \\ N Niikawa, N Matsumoto
}

M ental retardation (MR) occurs in $2-3 \%$ of the general population, and more than half of MR patients are categorised as idiopathic - that is, the cause is unknown. ${ }^{12}$ Patients with idiopathic MR are presumed to be affected with certain genetic disorders or undetectable chromosomal abnormalities. MR may also be caused by environmental factors independently or by their interaction with genetic factors. Subtelomeric rearrangements comprise about half of segmental aneusomies, ${ }^{3}$ and are one of the major causes of $\mathrm{MR}^{4}{ }^{5} \mathrm{~A}$ recent review showed that subtelomeric rearrangements were detected in 131 (5.1\%) of 2585 children with MR. ${ }^{14-6}$ Conventional cytogenetic analysis can detect many, but not all, rearrangements, depending on its powers of resolution. ${ }^{4}$ Other methods, such as fluorescent in situ hybridisation (FISH) using a complete set of subtelomeric probes, multicolour FISH (M-FISH), comparative genomic hybridisation (CGH), spectrum karyotyping, multiple amplifiable probe hybridisation, primed in situ labelling, and genotyping have been designed to detect subtelomeric rearrangements, but none of them is ideal in terms of sensitivity and/or efficiency. ${ }^{4} 6$ Microarray based $\mathrm{CGH}$ is a promising, high throughput method of detecting subtelomeric rearrangements. ${ }^{4}$ Veltman et al recently reported a microarray CGH system using crude bacterial/plasmid derived artificial chromosome (BAC/PAC) DNA for the analysis of subtelomeric aberrations, and suggested that degenerate oligonucleotide primed (DOP)-PCR products could also be used instead of crude clone DNA, although the performance of DOP-PCR products might be less sensitive. ${ }^{7}$ We have developed a microarray CGH system to identify rearrangements involving a subtelomeric region, using DOP-PCR that amplifies subtelomeric BAC/PAC DNA. Here we describe details of the method and the results of microarray CGH analyses of five cases of Wolf-Hirschhorn syndrome (WHS) associated with terminal $4 p$ deletions as positive controls, and of 69 patients with idiopathic MR with or without multiple congenital anomalies (MCA).

\section{MATERIALS AND METHODS}

Target DNA for microarray

BAC/PAC clones used in this study are shown in table 1 . We selected subtelomeric clones based on the second generation set of human chromosome specific subtelomeric probes reported by Knight et al. ${ }^{8}$ Five clones (GS-124I4 for 16p, GS-48O23 and GS-325I23 for 19q, GS-82O2 for 20p, and GS$202 \mathrm{M} 24$ for $\mathrm{Xq}$ ) that showed signals appearing at sites different from those originally reported were excluded from this study. Three clones (GS-99K24, CITD-3018K1 for 22q, and GS-225F6 for XqYq) were unavailable. New clones (RP11-359B7 for 19q, RP11-238J15 for 20p, RP3-402G11 for

\section{Key points}

- We have developed a microarray based comparative genomic hybridisation (CGH) assay using bacterial and plasmid derived artificial chromosome clones mapped uniquely to each subtelomeric region of human chromosomes.

- To confirm the reliability of detecting cryptic subtelomeric rearrangements, we analysed five cases of WolfHirschhorn syndrome (WHS) that were known to have a distal $4 p$ deletion. The microarray $\mathrm{CGH}$ system successfully enabled us to reveal that two of the five WHS cases had $5 q$ or $10 q$ trisomy in addition to the $4 p$ deletions present in all.

- We then analysed 69 subjects with idiopathic mental retardation (MR), whose karyotype was normal by conventional $G$ banding analysis. The microarray successfully disclosed cryptic subtelomeric rearrangements in $4(5.8 \%)$ of the 69 patients.

- All these abnormalities showed a fluorescent signal intensity ratio (Cy3/Cy5) beyond the 2SD range, and were subsequently confirmed by conventional fluorescent in situ hybridisation using subtelomere specific BAC/PAC clones. Their karyotypes were ish dup(12)(p13.3p13.3)mat; ish del(9)(q34.3)de novo; ish $\operatorname{der}(5)+(5 ; 20)(\mathrm{p} 15.33 ; \mathrm{p} 13)$ pat; and ish $\operatorname{der}(10)+(10 ; 12)(q 26.3 ; p 13)$.

- The microarray CGH we have developed is a rapid and high throughput system and provides a promising way to find subtelomeric rearrangements in patients with idiopathic MR or MCA of unknown cause.

22q, and RP11-431N21 for XqYq) were obtained from online databases, the human telomere mapping and sequencing project (http://www.wistar.upenn.edu/Riethman/) and the human genome browser (http://genome.ucsc.edu/cgi-bin/ hgGateway? $\mathrm{Db}=$ hgl1). Although RP1l-431N21 mapped to $\mathrm{Xq} / \mathrm{Yq}$ showed unequal signal intensities between $\mathrm{Xq}$ and

Abbreviations: ANILFR, average normalised inter-locus fluorescence ratio; $\mathrm{BAC}$, bacterial artificial chromosome; $\mathrm{CGH}$, comparative genomic hybridisation; DOP, degenerate oligonucleotide primed; FISH,

fluorescent in situ hybridisation; M-FISH, multicolour FISH; MR, mental retardation; PAC, plasmid derived artificial chromosome; WHS, WolfHirschhorn syndrome 


\begin{tabular}{|c|c|c|}
\hline Locus & Clone ID & Clone type \\
\hline 1pter & GS-232B23 & BAC \\
\hline lqter & GS-160H23 & PAC \\
\hline 2 pter & GS-8L3 & BAC \\
\hline $2 q$ ter & СІTВ-172113 & BAC \\
\hline 3pter & СІTВ-228K22 & BAC \\
\hline $3 q$ ter & GS-56H22 & BAC \\
\hline 4pter & GS-36P21 & PAC \\
\hline 4qter & GS-31J3 & BAC \\
\hline 5 pter & GS-189N21 & PAC \\
\hline 5 qter & GS-240G13 & PAC \\
\hline 6pter & GS-62111 & PAC \\
\hline 6qter & GS-57H24 & PAC \\
\hline 7 pter & GS-164D18 & PAC \\
\hline 7 qter & GS-3K23 & PAC \\
\hline 8pter & GS-77L23 & BAC \\
\hline 8 grer & GS-26111 & BAC \\
\hline 9 pter & GS-43N6 & PAC \\
\hline 9qter & GS-135117 & BAC \\
\hline 10 pter & GS-306F7 & PAC \\
\hline 10 qter & GS-137E24 & PAC \\
\hline 11 pter & GS- $44 \mathrm{H} 16$ & PAC \\
\hline 11 qter & GS-26N8 & PAC \\
\hline 12 pter & GS- $124 K 20$ & BAC \\
\hline $12 q$ ter & GS-221K 18 & PAC \\
\hline 13 gter & GS-163C9 & PAC \\
\hline $14 q$ ter & GS-200D12 & PAC \\
\hline 15 qter & GS-154P1 & PAC \\
\hline 16pter & CITB-191K2 & BAC \\
\hline 16qter & GS-240G10 & PAC \\
\hline 17pter & GS-68F18 & BAC \\
\hline 17 qter & GS-50C4 & BAC \\
\hline 18pter & GS-52MI 1 & $\mathrm{Pl}$ \\
\hline 18qter & GS-75F20 & BAC \\
\hline 19pter & СІTВ-129F16 & BAC \\
\hline 19 gter & RP11-359B7 & BAC \\
\hline 20pter & RP11-530N10 & BAC \\
\hline 20 qter & RP11-238J15 & BAC \\
\hline 21 qter & GS-63H24 & PAC \\
\hline 22qter & RP3-402G11 & PAC \\
\hline XpterYpter & GS-98C4 & PAC \\
\hline XqterYqter & RP11-431N21 & BAC \\
\hline Xp22.32 & RP11-26709 & BAC \\
\hline Xp22.3 & RP4-617A9 & BAC \\
\hline
\end{tabular}

Yq (FISH signals of Xq were twice as intense as those of Yq), we included it in our microarray because no other suitable clones could be obtained. In addition, we added two $\mathrm{X}$ chromosome specific clones (RP11-267O9 on Xp22.32 and RP4-617A9 on Xp22.3) as internal controls. Clones were purchased from either Incyte Genomics (Polo Alto, CA, USA) or Invitrogen (Carlsbad, CA, USA). DNA was extracted using QIAgen Plasmid Midi kits (QIAgen, Hilden, Germany) from $200 \mathrm{ml}$ bacterial culture with appropriate antibiotics according to the manufacturer's protocol.

\section{Degenerate oligonucleotide primed PCR}

DOP-PCR was performed to amplify target clone DNA using three different $5^{\prime}$-aminolabelled PCR primers, DOP-A (5'CCGACTCGAGNNNNNNATGTGG-3'), DOP-B (5'-CCGACTC GAGNNNNNNTTCACC-3'), and DOP-C: (5'-CCGACTCGAG NNNNNNAACAGG-3'). The sequence of DOP-A is the same as that of $6 \mathrm{MW}$ by Telenius et al. ${ }^{9}$ Two other primers were randomly designed and confirmed as capable of amplifying clone DNAs as effectively as DOP-A. Primers were purchased from Hokkaido System Science Co Ltd (Sapporo, Japan). DOP-PCR was performed in a $100 \mu \mathrm{l}$ cocktail containing $50 \mathrm{ng}$ BAC/PAC DNA, $1 \mu \mathrm{mol} / \mathrm{l}$ of a DOP primer, $3 \mathrm{mmol} / \mathrm{l}$ $\mathrm{MgCl}_{2}, 200 \mathrm{mmol} / \mathrm{l}$ of each dNTP, $1 \times$ ExTaq buffer (Takara Bio, Ohtsu, Japan), and $0.5 \mathrm{U}$ ExTaq ${ }^{\mathrm{TM}} \mathrm{HS}$ enzyme (Takara
Bio). PCR was cycled 30 times at $94^{\circ} \mathrm{C}$ for 30 seconds, at linear ramping of $37-72^{\circ} \mathrm{C}$ over 10 minutes, and at $72^{\circ} \mathrm{C}$ for 1 minute. Successfully amplified PCR products, usually $0.2-$ $2 \mathrm{~kb}$ in size, were used for subsequent experiments. Using DOP-A, DOP-B, or DOP-C, each PCR product $(100 \mu \mathrm{l})$ was mixed with the same volume $(300 \mu \mathrm{l})$ of $4 \times$ print buffer ( $1 \mathrm{~mol} / \mathrm{l}$ sodium phosphate $/ 0.001 \% \mathrm{~N}$-lauroyl sarcosine, $\mathrm{pH}$ 8.5) and concentrated to a final volume of $30 \mu \mathrm{l}$ using Microcon 100 (Millipore, Bedford, MA, USA). The products were mixed with DMSO and $\mathrm{ddH}_{2} \mathrm{O}$ to a final concentration of $1 \times$ print buffer $/ 20 \%$ DMSO and were ready for prints.

\section{Subject DNA}

Genomic DNA from 69 cases of idiopathic MR, whose karyotype was normal by $\mathrm{G}$ banding chromosome analysis at the 400 band level, was analysed. MCA was seen in all subjects except one, but recognisable syndromes were ruled out by at least one of the co-authors. We also used DNA from five patients with WHS (WHS1-5), who had been diagnosed as having various deletions for distal $4 \mathrm{p}$, as positive controls to examine the reliability of the microarray CGH system described below (table 2), and that from normal controls as reference DNA for the system.

\section{Microarray CGH}

Each product was spotted in triplicate onto CodeLink ${ }^{\mathrm{TM}}$ activated slides (Amersham Bioscience, Buckinghamshire, UK) using Stampman (Nippon Laser and Electronics Laboratory, Nagoya, Japan) with a centre to centre distance of $1 \mathrm{~mm}$ between adjacent spots. The same triplicate spots were printed twice to block A and block B on the same slide. The slides were then pretreated, ${ }^{10}$ denatured, and stored in a desiccator until use. Subjects' DNA was labelled with Cy3, and control DNA with Cy5 (CGH 1). Reverse labelling (patient DNA with Cy5, and control DNA with Cy3) was also performed (CGH 2). BamHI digested genomic DNA $(1 \mu \mathrm{g})$ was labelled with Cy5 or Cy3 dCTP by random prime labelling. Differentially labelled DNA was mixed with $67.5 \mu \mathrm{g}$ CotI DNA (Invitrogen, Tokyo, Japan), and suspended with $60 \mu \mathrm{l}$ hybridisation buffer (50\% formamide, $10 \%$ dextran sulfate, $0.1 \%$ Tween $20,2 \times \mathrm{SSC}, 10 \mathrm{mmol} / \mathrm{l}$ Tris-HCl; $\mathrm{pH} 7.4$ ) with $60 \mu \mathrm{g}$ yeast tRNA (Roche, Basel, Switzerland). After prehybridisation with herring sperm DNA and human CotI DNA using an in situ frame (Eppendorf, Hamburg, Germany)

\begin{tabular}{|c|c|c|}
\hline Patient & Previous karyotype & $\begin{array}{l}\text { Confirmed karyotype } \\
\text { by combined results of } \\
\text { microarray CGH and FISH }\end{array}$ \\
\hline \multicolumn{3}{|l|}{ WHS } \\
\hline WHS1 & $\begin{array}{l}46, X Y, \text { del }(4)(p 16) \mathrm{de} \\
\text { novo }\end{array}$ & $\begin{array}{l}46, X Y \text {.ish der }(4)+(4 ; 10) \\
(\mathrm{pl} 6 ; \mathrm{q} 26) \text { de novo }\end{array}$ \\
\hline WHS2 & $46, X Y \operatorname{del}(4)(p 16)$ & $\begin{array}{l}46, X Y, \operatorname{der}(4)+(4 ; 5) \\
\text { (p15.3;q35.1)pat }\end{array}$ \\
\hline WHS3 & $\begin{array}{l}\text { 46,XX,del(4)(p16.1).ish } \\
\text { del(4)(p16.3)(D4S96-) }\end{array}$ & Same as above \\
\hline WHS4 & $46, X Y$, del(4)(p15.3) & Same as above \\
\hline WHS5 & $\begin{array}{l}46, X X \text {, del(4)(p15.2)de } \\
\text { novo }\end{array}$ & Same as above \\
\hline \multicolumn{3}{|c|}{ 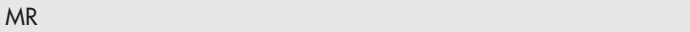 } \\
\hline N02R245 & Normal & $\begin{array}{l}\text { 46,XX.ish dup(12) } \\
\text { (p13.33p13.33)mat }\end{array}$ \\
\hline N03R003 & Normal & $46, X Y$. ish del(9)(q34.3) de novo \\
\hline N03R017 & Normal & $\begin{array}{l}\text { 46,XY.ish der(5)t(5;20) } \\
\text { (p15.33;p13)pat }\end{array}$ \\
\hline N03R088 & Normal & $\begin{array}{l}46, X X, \operatorname{der}(10)+(10 ; 12) \\
(q 26.3 ; p 13.1)\end{array}$ \\
\hline
\end{tabular}

WHS, Wolf-Hirschhorn syndrome; MR, mental retardation. 
surrounding each block on a slide in a hybridisation chamber (Genetix, New Milton, UK), labelled probe mixtures of CGHI and CGH2 were simultaneously applied to blocks A and B, respectively. Slides were incubated at $37^{\circ} \mathrm{C}$ for 72 hours with gentle shaking ( $5 \mathrm{rpm})$, and then washed twice with solution A $(1 \times$ PBS with $0.05 \%$ Tween 20$)$ for 10 minutes at room temperature, twice with solution B $(2 \times$ SSC with $50 \%$ formamide) at $43^{\circ} \mathrm{C}$ for 15 minutes, and finally with solution $\mathrm{A}$ at room temperature for 10 minutes. Slides were scanned with GenePix 4000B (Axon Instruments Inc, Union City, CA, USA) and analysed with GenePix Pro 4.0 software (Axon Instruments Inc).

The intensity ratio between patient and control DNA was calculated from the data of the single slide experiment, using the ratio of means formula. Average normalised inter-locus fluorescence ratio (ANILFR) ${ }^{11}$ was calculated for each CGH. We had previously performed five sets of CGH experiments with two different normal DNA samples in order to evaluate the thresholds for copy number gain and loss, which showed that the average ANILFR of each clone ranged from 0.86 to 1.18, with an SD of 0.06. Based on this, the normal ANILFR range was defined as numbers within 2SD. This configuration was verified by the fact that the ANILFR of all clones excluding unique $\mathrm{X}$ chromosomal clones were within 2SD (fig 1A). If the mean signal ratio on each spot of clone was more than 2SD out of range, FISH analysis was subsequently performed.

\section{FISH analysis}

Subtelomeric BAC/PAC DNA labelled with either SpectrumOrange ${ }^{\mathrm{TM}}$ dUTP or SpectrumGreen ${ }^{\mathrm{TM}}$ dUTP (Vysis,
Downers Grove, IL, USA) by nick translation was used for FISH analysis. Probes were denatured and hybridised to metaphase chromosomes of patients at $37^{\circ} \mathrm{C}$ for 16 hours and washed. Photoimages were captured using a monochrome CCD camera (Carl Zeiss, Jena, Germany) on an Axioplan 2 fluorescence microscope (Carl Zeiss) with appropriate filters, and were analysed with ISIS software (version 3.4.5; MetaSystems, Altlussheim, Germany). All five WHS cases were analysed using all subtelomeric clones to confirm the results of the microarray analysis. In MR patients, specific subtelomeric probes were used for FISH analysis where a deletion or a duplication was suspected.

\section{RESULTS}

\section{Patients with WHS}

Five cases of WHS were analysed as positive controls by microarray CGH and FISH using all subtelomeric probes. As expected, using microarray CGH with the $4 \mathrm{p}$ subtelomeric clone, GS-36P21, the signal ratios for the patients were beyond the $2 \mathrm{SD}$ range (fig $1 \mathrm{~B}-\mathrm{F}$ ), and all were confirmed to have a deletion at the GS-36P21 site. In addition, other subtelomeric aberrations were suspected by microarray analysis - that is, a $10 \mathrm{q}$ duplication in WHS1 and a $5 \mathrm{q}$ duplication in WHS2 (fig $1 \mathrm{~B}, \mathrm{C}$ ). FISH using respective subtelomeric clones confirmed these aberrations. The parents of WHS1 and the mother of WHS2 were normal by FISH studies, but the father of WHS2 had a balanced translocation between $4 \mathrm{p}$ and $5 \mathrm{q}$. High resolution $\mathrm{G}$ banding analysis indicated his karyotype to be $46, \mathrm{XY}, \mathrm{t}(4 ; 5)(\mathrm{pl} 5.3 ; \mathrm{q} 35.1)$. Thus, the karyotypes of WHS1 and 2 were interpreted as $46, \mathrm{XY}$.ish $\operatorname{der}(4) \mathrm{t}(4 ; 10)(\mathrm{pl} 6 ; \mathrm{q} 26) \mathrm{de}$ novo and

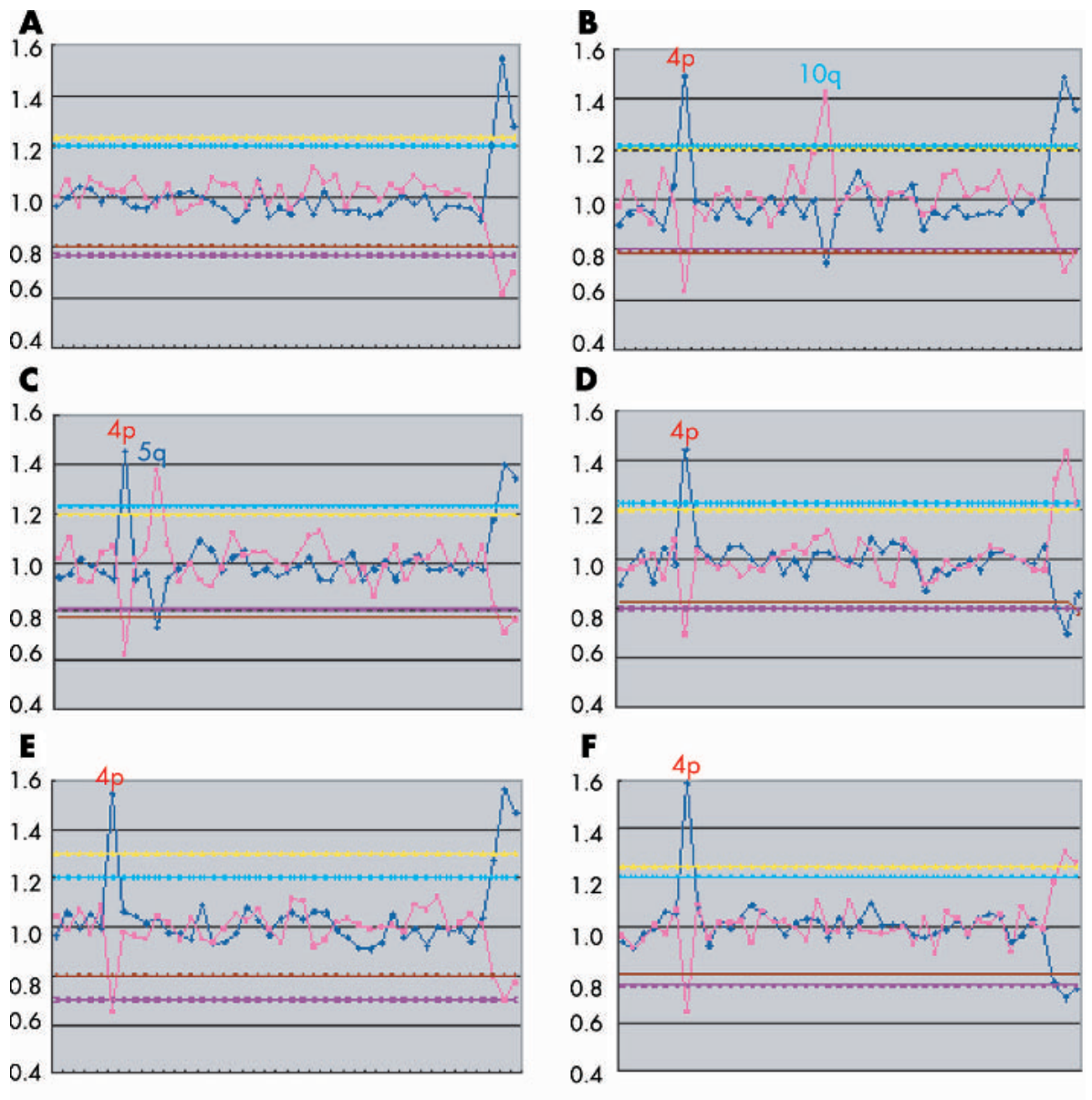

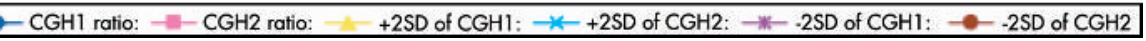

Figure 1 Microarray $\mathrm{CGH}$ profiles in a normal control and five cases of WHS. (A), (B), (C), (D), (E), and (F) indicate microarray CGH profiles in a normal male and in WHS1, 2, 3, 4, and 5 , respectively. Horizontal axis, left to right: subtelomeric clones mapped to $1 p, 1 q, 2 p, 2 q, 3 p, 3 q, 4 p, 4 q, 5 p, 5 q$, $6 p, 6 q, 7 p, 7 q, 8 p, 8 q, 9 p, 9 q, 10 p$, $10 q, 11 p, 11 q, 12 p, 12 q, 13 q, 14 q$ $15 q, 16 p, 16 q, 17 p, 17 q, 18 p, 18 q$ $19 p, 19 q, 20 p, 20 q, 21 q, 22 q, X p / Y p$, $\mathrm{Xq} / \mathrm{Yq}$, and clones covering STS at $\mathrm{Xp22.32}$ and ARSE at Xp22.3. Vertical axis showed the $\mathrm{CGH}$ ratio $(\mathrm{Cy} 5 / \mathrm{Cy} 3)$ at each locus. $\mathrm{CGH} 1$ was performed by hybridisation of Cy3 labelled test DNA (patient) and $\mathrm{Cy} 5$ labelled reference DNA (normal control of opposite sex). CGH2 was hybridised with $\mathrm{Cy} 5$ labelled test DNA (patient) and Cy3 labelled reference DNA (normal control of opposite sex). Chromosomal gains and losses found were shown as blue and red characters, respectively. All rearrangements were clearly detected as ratios beyond the $2 \mathrm{SD}$ range. All WHS cases clearly showed their terminal $4 \mathrm{p}$ deletions (B-F). WHSI and 2 also showed subtelomeric duplications of $10 q$ and $5 q$ respectively $(B, C)$. Internal reference clones in the $\mathrm{X}$ chromosome were also indicated as ratios beyond the 2SD range because of being the opposite sex. 
46,XY,der(4)t (4;5)(p15.3;q35.1)pat, respectively (table 2 ). In order to verify the accuracy of these micorarray CGH data, all subtelomeric regions were investigated by FISH in the five WHS cases, which confirmed the CGH data and supported the reliability of the method (table 2 ).

\section{Idiopathic MR patients}

We analysed 69 cases of idiopathic MR with or without MCA by microarray $\mathrm{CGH}$. Subtelomeric rearrangements were detected in the following four cases (5.8\%): N02R245, N03R003, N03R017, and N03R088 (table 2).

\section{$\mathrm{N} 02 \mathrm{R} 245$}

A 2 year old girl was the second child of non-consanguineous healthy parents without any family history of MR or congenital anomalies. Her birth at 38 gestational weeks was uneventful, with a birthweight of $3130 \mathrm{~g}(+0.3 \mathrm{SD})$, length of $50 \mathrm{~cm}(+1 \mathrm{SD})$ and Apgar score of 9 at 5 minutes. She showed moderate developmental delay. She could control her head at 5 months of age, and sit at 10 months, but could neither walk nor speak any meaningful words at 19 months. At the age of 21 months, her height was $80 \mathrm{~cm}$ (25th percentile), weight $9.6 \mathrm{~kg}$ (25th percentile), and head circumference $49 \mathrm{~cm}$ (90th percentile). Minor facial anomalies noted included epicanthal fold, depressed nose, low nasal bridge, and thin upper lip. A brain MRI study at 10 months did not reveal any abnormalities. A chromosomal gain of a $12 p$ subtelomeric region was detected by microarray CGH (fig 2A). FISH analysis on metaphase chromosomes using the $12 \mathrm{p}$ subtelomeric clone GS-124K20 revealed that a signal on one homologous chromosome 12 was twice as large as that on the other (fig 3A), and duplicated signals and a separate single signal were detected on interphase cells (fig 3A), suggesting that tandem duplication of a $12 p$ subtelomeric region had occurred. A similar finding was observed in her mother, whose phenotype was normal, but it was not observed in her father. High resolution $\mathrm{G}$ banding analysis of the patient and her mother did not reveal any differences in chromosome 12 (fig $4 \mathrm{~A}$ ). In order to see whether the $12 \mathrm{p}$ duplication was a normal variant, FISH analysis using GS-124K20 as the probe was performed on 50 normal Japanese controls, none of which showed the duplication.

\section{N03R003}

An 8 year old boy had severe MR, seizures, microcephaly, dysmorphic face, and other anomalies. Detailed clinical information has been described elsewhere as patient $2 .{ }^{12}$ Chromosomal deletion of a $9 \mathrm{q}$ subtelomeric region was detected by micorarray CGH (fig 2B), and was confirmed by FISH using a 9q subtelomeric probe as described previously ${ }^{12}$ (fig 3B). As FISH analysis confirmed that neither of his parents had such a deletion, it was considered a de novo mutation. $\mathrm{G}$ banding chromosome analysis could not identify the deletion in the patient (fig 4B).

\section{N03R017}

A 15 month old boy was the first child of non-consanguineous healthy parents without any family history of MR or congenital anomaly. His birth at 39 gestational weeks was uneventful. His birth weight was $3046 \mathrm{~g}$ (+0.25 SD), birth length $52 \mathrm{~cm}(+1.5 \mathrm{SD})$, and Apgar score 9 at 5 minutes. He presented with severe developmental delay. He could control his head at 5 months of age, and sit at 12 months, but could neither walk nor speak any meaningful words at 14.5 months old. At 1 year of age, his height was $75 \mathrm{~cm}$ (50th percentile), and weight $7.8 \mathrm{~kg}$ (3rd percentile). Minor craniofacial anomalies were microcephaly, flat occiput, epicanthal folds, depressed nasal root, long philtrum, low set ears, and micrognathia. Infantile leukaemia was observed at the age of 10 months, and chemotherapy was performed. A subtelomeric chromosomal deletion of $5 p$ and a gain of $20 p$ were detected by microarray CGH (fig 2C), and were confirmed by FISH (fig 3C). FISH analysis of his parents revealed that his phenotypically normal father showed a balanced translocation between $5 \mathrm{p}$ and 20p, but no morphological difference between homologous chromosomes 5 and 20 was observed by G banding analysis (fig 4C).

\section{N03R088}

A 6 year old girl was born at 41 gestational weeks uneventfully. Her birth weight was $3020 \mathrm{~g}$ (-1 SD), birth
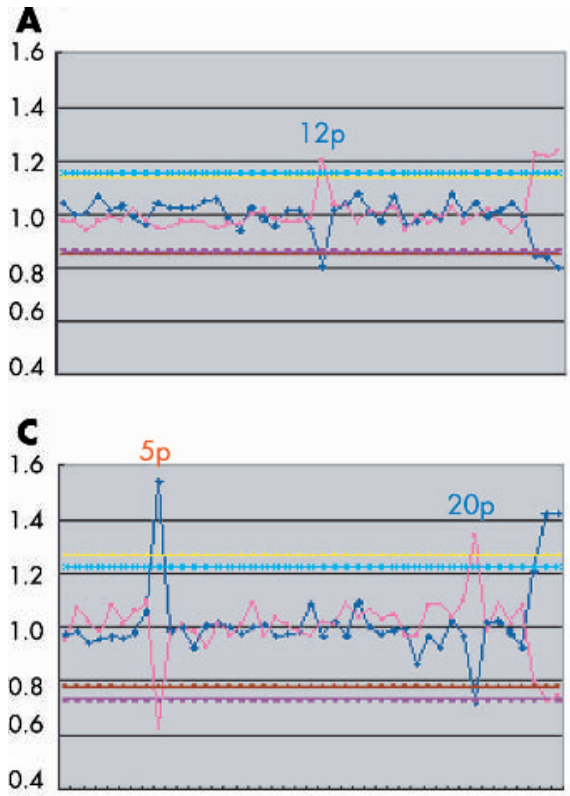

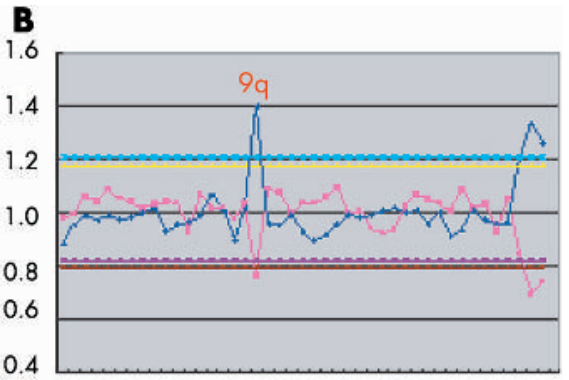

D

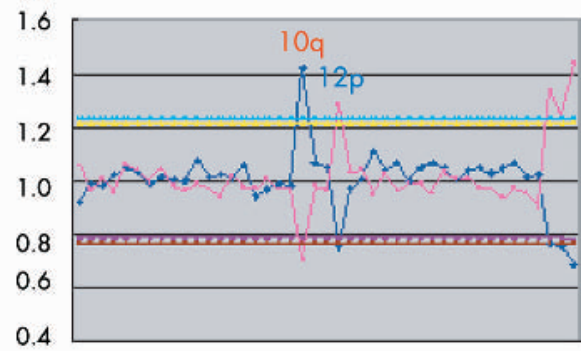

Figure 2 Microarray $\mathrm{CGH}$ in idiopathic MR cases. (A), (B), (C), and (D) show the results of microarray $\mathrm{CGH}$ on N02R245, N03R003, N03R017, and N03R088, respectively. Chromosomal gains and losses identified are shown as blue and red characters, respectively. Abnormal rearrangements were clearly detected as a $\mathrm{CGH}$ ratio beyond the $2 \mathrm{SD}$ range of ANILFR. (A) Duplication of 12p; (B) deletion of $9 q ;(C)$ deletion of $5 p$ and duplication of 20p; (D) deletion of $10 q$ and duplication of $12 p$. 

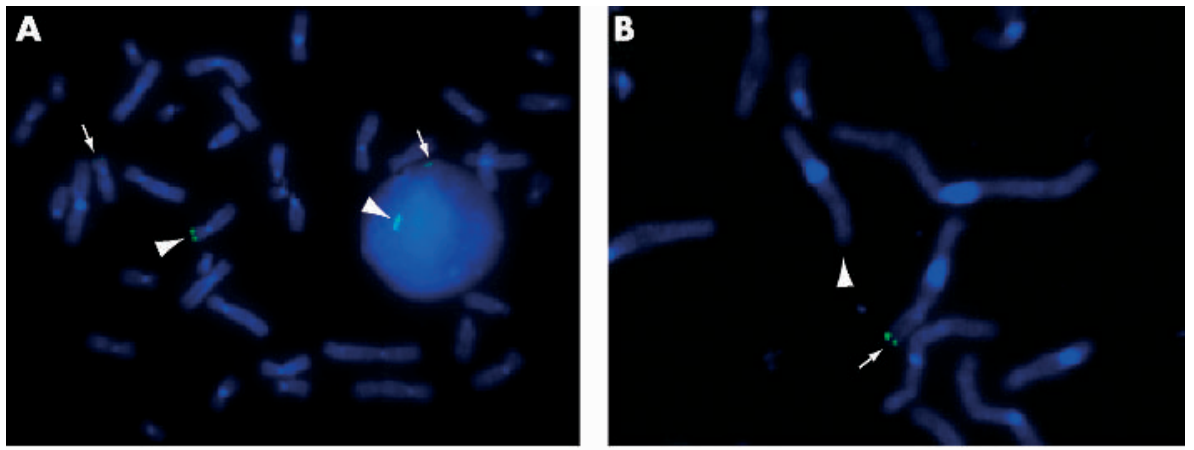

Figure 3 FISH studies confirming chromosomal abnormalities that were detected by micorarray $\mathrm{CGH}$ in idiopathic MR cases. (A), (B), (C), and (D) show the results of the FISH analysis to confirm the microarray $\mathrm{CGH}$ detected rearrangements. (A) A subtelomeric clone for 12p (GS 124K20; green) was hybridised to metaphase chromosomes from N02R245. The arrow and arrowhead indicate a signal of a normal

chromosome and that of its counterpart chromosome with a duplication, respectively. (B) A 9q subtelomeric
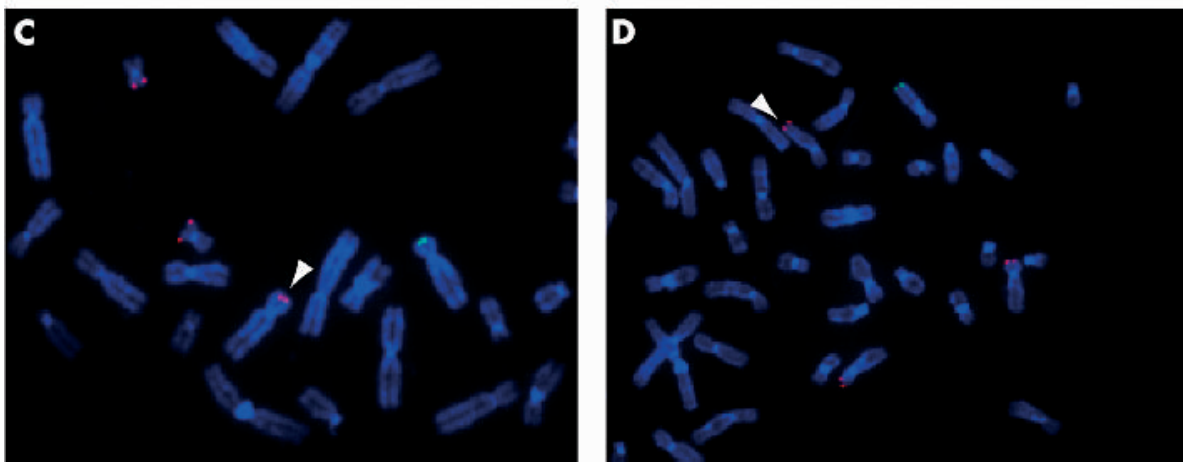
clone (GS-135117; green) was hybridised to chromosomes of N03R003. The arrow indicates a signal on chromosome 9, and the arrowhead shows a deletion. (C) Subtelomeric clone of 5p (GS-189N21; green) and subtelomeric clone for 20p (RP1 1$530 \mathrm{~N} 21$; orange) were hybridised to chromosomes of N03R017. The arrowhead indicates a derivative chromosome, ish $\operatorname{der}(5)+(5 ; 20)$ (p15.33;p13)pat. (D) Subtelomeric clones for 10q (GS137E24; green) and for $12 p$ (GS 124K20; orange) were hybridised to chromosomes of N03R088. The arrowhead indicates a derivative chromosome, $\operatorname{der}(10)+(10 ; 12)(q 26.3 ; p 13.1)$.

length $47 \mathrm{~cm}(-1.5 \mathrm{SD})$, and Apgar score 9/10 at 1 and 5 minutes. She was the second child of non-consanguineous healthy parents. She showed general hypotonia and severe developmental delay. She could control her head at 6 months of age, roll over at 9 months, and sit at 4 years, but could neither walk nor speak any meaningful words at 6 years of age. She had febrile seizures that occurred at 1 year of age, but never developed epilepsy. Craniofacial abnormalities were noted: flat occiput, square shaped face, hypertelorism, low set ears, downturned corners of the mouth, cleft soft palate, and micrognathia. Brain MRI revealed mild dilatation of the lateral ventricles, cavum septum pellucidi, and cavum vergae. A sacral dimple was identified, but MRI could not reveal any gross abnormalities. Microarray CGH analysis detected a subtelomeric chromosomal deletion of 10q and a gain of $12 p$ (fig $2 \mathrm{D}$ ), which were subsequently verified by FISH (fig 3D). High resolution $G$ banding analysis revealed that her karyotype was 46,XX,der(10)t(10;12)(q26.3;p13.1) (fig 4D). A parental origin of the unbalanced translocation was not confirmed because parental materials were unavailable.

\section{DISCUSSION}

Molecular studies focusing on cryptic subtelomeric rearrangements in idiopathic MR patients have been performed mainly by FISH using subtelomere specific probes, and genotyping using hypervariable genetic markers. ${ }^{14-6}$ Microarray CGH, a high throughput technology, was developed to identify changes in copy number of chromosomal segments or genes not only in somatic events (neoplasms), but also in germline derived events (constitutional chromosomal changes). ${ }^{13-18}$ Recently, Veltman et al showed the efficiency of subtelomere specific microarray CGH in detecting known and novel cytogenetic abnormalities. ${ }^{7}$ We have developed subtelomere specific microarray CGH for MR. Its accuracy has been confirmed using five cases of WHS as positive controls, and we applied it to analysis of 69 patients with idiopathic MR. All the WHS cases showed a $4 \mathrm{p}$ subtelomeric deletion, and two were found to have either a $10 \mathrm{q}$ or a $5 \mathrm{q}$ duplication by microarray CGH. Four $(5.8 \%)$ of 69 cases of idiopathic MR were found to have subtelomeric rearrangements, the frequency being consistent with the data from recent reports. ${ }^{14-6}$ The accuracy of our microarray CGH was verified by FISH using all subtelomeric probes in the five WHS cases; the genomic rearrangements were not overlooked by our microarray CGH in any of them. ANILFR of clones with either a deletion or a duplication, and in those without changes of the copy number were $0.628,1.433$, and 0.995 , respectively, in all the patients. The two former ratios were beyond the 2SD range, while all other clones were within the range (figs 1 and 2). We used three different DOPPCR primers, DOP-A (the original primer developed by Telenius et al and named as $\left.6 \mathrm{MW}^{9}\right), \mathrm{DOP}-\mathrm{B}$, and DOP-C (both originally designed by us). DOP-PCR products using these primers should represent original clones more faithfully than those using a single DOP primer. Similarly, Fiegler et al ${ }^{10}$ adopted DOP-PCR using three different primers designed to amplify human specific DNA instead of contaminated bacterial DNA, and showed efficient detection of gains and deletions in a cancer cell line. Although our primers, DOP-B and DOP-C, were not designed for human specific DNA, DOP-PCR using the three primers was suitable for generating DNA for microarray. In addition, using the two simultaneous, independent hybridisations, $\mathrm{CGH} 1$ and $\mathrm{CGH} 2$, on one glass slide can eliminate conflicting results due to different conditions in each hybridisation, and detect genomic gains and deletions easily, because the data complement each other.

As well as the common $4 \mathrm{p}$ deletion, additional chromosomal abnormalities were detected in two (WHSl and 2) of five WHS patients. Both showed a typical WHS phenotype, suggesting that the WHS critical region could be the "master" regulatory sequence on clinical manifestations with a strong pleiotropic effect, ${ }^{19}$ or that the effects of $10 \mathrm{q} 26$ duplication and 5q35.3 duplication could be minimal.

Cryptic subtelomeric rearrangements were detected in 4 of the 69 cases of idiopathic MR (table 2). A 9q34.3 terminal 


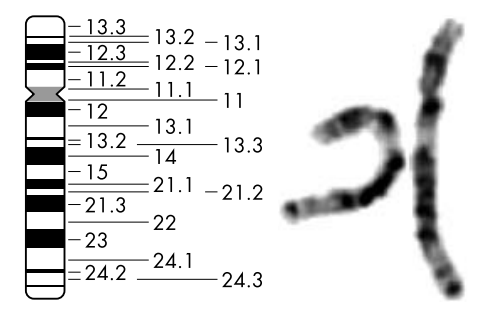

12

C
B

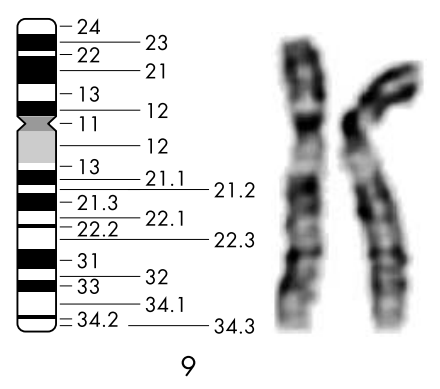

Figure 4 Partial karyotypes of rearranged chromosomes detected in MR cases. (A), (B), (C), and (D) show $G$ banded partial karyotypes of $\mathrm{N} 02 \mathrm{R} 245, \mathrm{~N} 03 \mathrm{RO03}$, the father of N03R017, and N03R088, respectively. (A-C) No morphological changes were noted between homologous chromosomes; (D) an unbalanced translocation, $\operatorname{der}(10)+(10 ; 12)(q 26.3 ; p 13.1)$, was recognised by high resolution $G$ banding analysis. The arrow indicates a 10q26.3 breakpoint.

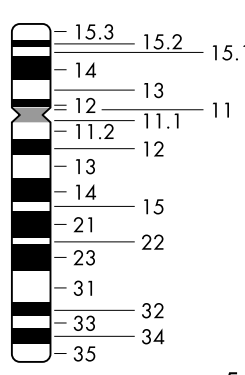

5

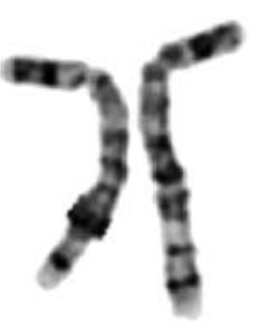

D

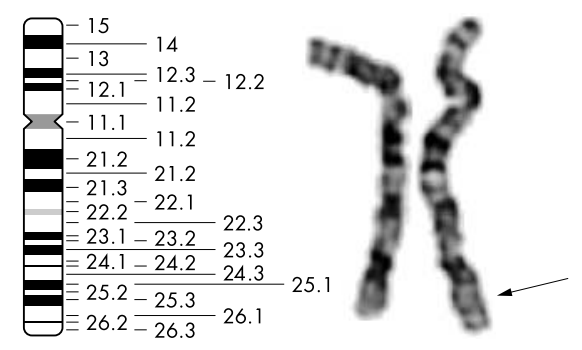

10

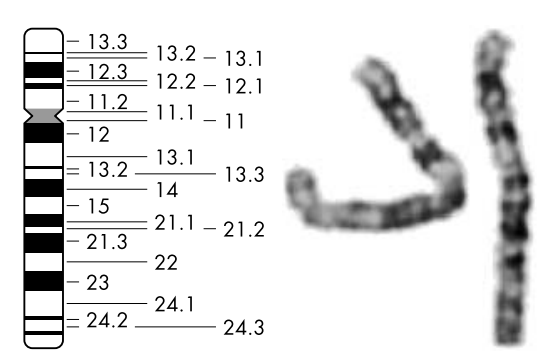

12 deletion was found in N03R003. This, together with the 4p terminal deletions identified in three WHS (WHS3, 4, and 5), might have originated from hidden unbalanced translocations that our microarray system could not detect. If so, breakpoints might exist distal to the subtelomeric clones that were used in microarray CGH. However, as each subtelomeric clone is located within $500 \mathrm{~kb}$ of the chromosomal end, a phenotypic effect of a hidden duplication derived from the unbalanced translocation may be subtle. A tandem duplication (ish $\operatorname{dup}(12)(\mathrm{p} 13.33 \mathrm{pl}$ 13.33)mat) detected in N02R245 may be a normal variant, because her phenotypically normal mother had the same abnormality, but we could not detect this duplication among 50 normal Japanese controls. Further FISH analysis using other BAC clones mapped at 12pl3.33 showed that the duplicated region was mapped to a region $0-530 \mathrm{~kb}$ proximal to the $12 \mathrm{p}$ telomeric end according to the UCSC genome browser (data not shown), but the orientation (inverted or directed) of the tandem duplication was uncertain. Two unbalanced translocations, ish $\operatorname{der}(5) \mathrm{t}(5 ; 20)$ (p15.33;pl3)pat in N03R017 and $\operatorname{der}(10) \mathrm{t}(10 ; 12)(\mathrm{q} 26.3 ; \mathrm{pl} 3.1)$ in N03R088, were detected. The origin of the latter remained unknown because parental materials were not available. The $5 \mathrm{p}$ subtelomeric deletion in N03R017 merits comment; a BAC clone covering CTNND2 encoding delta-2 catenin associated with the critical deleted region of cri du chat syndrome $(\mathrm{CdCS})^{20}$ was not deleted in this patient (Okamoto, in preparation), supporting the absence of any CdCS phenotypes and indicating that the $5 p$ deletion was less than $1.1 \mathrm{Mb}$ distance from the 5p telomere. In N03R088, who had a 10q26.3 deletion, a triangular face was not observed as previously reported. ${ }^{21}$ A five item checklist was proposed by de Vries et al to improve the detection rate of subtelomeric rearrangements in MR subjects. ${ }^{22}$ Retrospective scoring using the checklist revealed that the mean score in our 69 cases was 5.8, and scores in N02R245, N03R003, N03R017, and N03R088, who had subtelomeric rearrangements, were 2, 6, 6 , and 6, respectively. These figures support the previous findings, which showed that a score of 3 or higher had a sensitivity of $100 \%$ with rather low specificity of $27 \%$ and was therefore recommended as the cut off point. ${ }^{22}$ Several types of chromosomal aberrations were recently reported to be related to the olfactory receptor (OR) gene clusters at 8p23 and $4 \mathrm{pl} 16$. A common inversion polymorphism between two of these clusters at 8p23 exists in the normal population, and mothers heterozygous for the inversion may have a risk of bearing children with a complex rearrangement, inv dup del $(8 p) .^{23}{ }^{24}$ A similar inversion between two OR clusters at $4 \mathrm{pl} 6$ has also been found. ${ }^{25}$ Mothers with double heterozygous inversions at $8 \mathrm{p} 23$ and $4 \mathrm{p} 16$ tend to have an increased risk of $\mathrm{t}(4 ; 8)(\mathrm{pl} 6 ; \mathrm{p} 23)$ in their offspring, ${ }^{25}$ and children with $\operatorname{der}(4) \mathrm{t}(4 ; 8)(\mathrm{p} 16 ; \mathrm{p} 23)$ may suffer from WHS owing to distal $4 \mathrm{p}$ deletions. ${ }^{26-28}$ However no such translocation was found in our cases. To detect all submicroscopic chromosomal abnormalities, construction of a high resolution genomic microarray covering the whole genome is required..$^{13} 1416$ Buckley et al reported a full coverage microarray for 
chromosome 22 facilitating successful detection of genomic aberrations in acral melanoma, dermatofibrosarcoma, DiGeorge syndrome, and neurofibromatosis type $2 .{ }^{17}$ We are now developing a high resolution microarray system that covers the whole human genome and are planning to identify genes responsible for genetic disorders including MR and MR related syndromes as research bases. In the near future, such microarrays targeting the whole genome including subtelomeric regions may be used in clinical diagnosis.

\section{ACKNOWLEDGEMENTS}

Authors wish to thank Ms Yasuko Noguchi, Naoko Yanai, Kazumi Miyazaki, Naoko Takaki for their excellent technical assistance. N Matsumoto is supported by Grant-in-aid No. 14572143 for Scientific Research from the Ministry of Education, Culture, Sports, Science, and Technology and Research Grant 15B-4 for Nervous and Mental Disorders from the Ministry of Health, Labour and Welfare, and N Niikawa is supported by CREST from Japan Science and Technology Corporation (JST).

\section{Authors' affiliations \\ N Harada, K Yoshiura, N Niikawa, N Matsumoto, Department of} Human Genetics, Nagasaki University Graduate School of Biomedical Sciences, Nagasaki, Japan

N Harada, K Yoshiura, N Niikawa, N Matsumoto, CREST, Japan Science and Technology Corporation, Kawaguchi, Japan

N Harada, Y Kondoh, O Shimokawa, T Ida, Kyushu Medical Science Nagasaki Laboratory, Nagasaki, Japan

E Hatchwell, Genome Research Center, Cold Spring Harbor Laboratory, New York, USA

N Okamoto, Department of Planning and Research, Osaka Medical Center and Research Institute for Maternal and Child Health, Osaka, Japan

M Tsukahara, Faculty of Health Science, Yamaguchi University School of Medicine, Ube, Japan

K Kurosawa, Division of Medical Genetics, Kanagawa Children's Medical Center, Yokohama, Japan

H Kawame, Division of Medical Genetics, Nagano Children's Hospital, Nagano, Japan

T Kondoh, Department of Pediatrics, Nagasaki University Graduate School of Biomedical Sciences, Nagasaki, Japan

H Ohashi, Division of Medical Genetics, Saitama Children's Medical Center, Saitama, Japan

R Tsukino, Division of Pediatrics, Arida Municipal Hospital, Wakayama, Japan

T Nagai, Department of Pediatrics, Koshigaya Hospital, Dokkyo University School of Medicine, Koshigaya, Japan

Y Fukushima, Department of Medical Genetics, Shinshu University School of Medicine, Matsumoto, Japan

N Matsumoto, Department of Human Genetics, Yokohama City

University Graduate School of Medicine, Yokohama, Japan

Correspondence to: Dr N Matsumoto, Department of Human Genetics, Nagasaki University Graduate School of Biomedical Sciences, Sakamoto 1-12-4, Nagasaki 852-8523, Japan; naomat@yokohama-cu.ac.jp

\section{REFERENCES}

1 De Vries BB, Winter R, Schinzel A, Ravenswaaij-Arts C. Telomeres: a diagnosis at the end of the chromosomes. J Med Genet 2003:40:385-98.

2 Battaglia A. Genetics of mental retardation. Am J Med Genet 2003; 117C:1-2.

3 Borgaonkar DS. Chromosomal variation in man: a catalog of chromosomal variants and anomalies. New York: Wiley-Liss, 1997.

4 Biesecker LG. The end of the beginning of chromosome ends. Am J Med Genet 2002; 107:263-6.

5 Flint J, Knight S. The use of telomere probes to investigate submicroscopic rearrangements associated with mental retardation. Curr Opin Genet Dev 2003;13:310-16

$6 \mathrm{Xu} \mathrm{J}$, Chen Z. Advance in molecular cytogenetics for the evaluation of mental retardation. Am J Med Genet 2003;117C:15-24.

7 Veltman JA, Schoenmakers EF, Eussen BH, Janssen I, Merkx G, van Cleef B, van Ravenswaaij CM, Brunner HG, Smeets D, van Kessel AG. Highthroughput analysis of subtelomeric chromosome rearrangements by use of array-based comparative genomic hybridization. Am J Hum Genet 2002;70: 1269-76.
8 Knight SJ, Lese CM, Precht KS, Kuc J, Ning Y, Lucas S, Regan R, Brenan M, Nicod A, Lawrie NM, Cardy DL, Nguyen H, Hudson TJ, Riethman HC, Ledbetter DH, Flint J. An optimized set of human telomere clones for studying telomere integrity and architecture. Am J Hum Genet 2000;67:320-32.

9 Telenius H, Carter NP, Bebb CE, Nordenskjold M, Ponder BA, Tunnacliffe A. Degenerate oligonucleotide-primed PCR: general amplification of target DNA by a single degenerate primer. Genomics 1992;13:718-25.

10 Fiegler H, Carr P, Douglas EJ, Burford DC, Hunt S, Smith J, Vetrie D, Gorman P, Tomlinson IP, Carter NP. DNA microarrays for comparative genomic hybridization based on DOP-PCR amplification of BAC and PAC clones. Genes Chromosomes Cancer 2003;36:361-74.

11 Mantripragada KK, Buckley PG, Benetkiewicz M, de Bustos C, Hirvela C, Jarbo C, Bruder CEG, Wensman H, Mathiesen T, Nyberg G, Papi L, Collins VP, Ichimura K, Evans G, Dumanski JP. High-resolution profiling of an $11 \mathrm{Mb}$ segment of human chromosome 22 in sporadic schwannoma using array-CGH. Inter J Oncol 2003;22:615-22.

12 Iwakoshi M, Okamoto N, Harada N, Nakamura T, Yamamori S, Fujita H, Niikawa N, Matsumoto N. 9q34.3 deletion syndrome in three unrelated children. Am J Med Genet, 2003; in press.

13 Mohammed MS, Bejiani BA, Shah S, Lupski JR, Shaffer LG. Development and validation of a high-resolution genomic array for identifying constitutional chromosome abnormalities. Am J Hum Genet Supp/ 2001;69:176.

14 Sniiders AM, Nowak N, Segraves R, Blackwood S, Brown N, Conroy J, Hamilton G, Hindle AK, Huey B, Kimura K, Law S, Myambo K, Palmer J, Ylstra B, Yue JP, Gray JW, Jain AN, Pinkel D, Albertson DG. Assembly of microarrays for genome-wide measurement of DNA copy number. Nat Genet $2001 ; 29: 263-4$.

15 Bruder CE, Hirvela C, Tapia-Paez I, Fransson I, Segraves R, Hamilton G, Zhang XX, Evans DG, Wallace AJ, Baser ME, Zucman-Rossi J, Hergersberg M, Boltshauser E, Papi L, Rouleau GA, Poptodorov G, Jordanova A, RaskAndersen H, Kluwe L, Mautner V, Sainio M, Hung G, Mathiesen T, Moller C, Pulst SM, Harder H, Heiberg A, Honda M, Niimura M, Sahlen S, Blennow E, Albertson DG, Pinkel D, Dumanski JP. High resolution deletion analysis of constitutional DNA from neurofibromatosis type 2 (NF2) patients using microarray-CGH. Hum Mol Genet 2001;10:271-82.

16 Cai WW, Mao JH, Chow CW, Damani S, Balmain A, Bradley A. Genomewide detection of chromosomal imbalances in tumors using BAC microarrays. Nat Biotechnol 2002;20:393-6.

17 Buckley PG, Mantripragada KK, Benetkiewicz M, Tapia-Paez I, Diaz De Stahl T, Rosenquist $M$, Ali H, Jarbo $C$, de Bustos $C$, Hirvela $C$, Sinder Wilen B, Fransson I, Thyr C, Johnsson BI, Bruder CE, Menzel U, Hergersberg M, Mandahl N, Blennow E, Wedell A, Beare DM, Collins JE, Dunham I, Albertson D, Pinkel D, Bastian BC, Faruqi AF, Lasken RS, Ichimura K, Collins VP, Dumanski JP. A full-coverage, high-resolution human chromosome 22 genomic microarray for clinical and research applications. Hum Mol Genet 2002:11:3221-9.

18 Veltman JA, Jonkers $Y$, Nuijten I, Janssen I, van der Vliet W, Huys E, Vermeesch J, van Buggenhout G, Fryns JP, Admiraal R, Terhal P, Lacombe D, van Kessel AG, Smeets D, Schoenmakers EF, van Ravenswaaij-Arts CM. Definition of a critical region on chromosome 18 for congenital aural atresia by array CGH. Am J Hum Genet 2003:72:1578-84.

19 Zollino M, Wright TJ, Di Stefano C, Tosolini A, Battaglia A, Altherr MR, Neri G. "Tandem" duplication of 4p16.1p16.3 chromosome region associated with 4 p16.3pter molecular deletion resulting in Wolf-Hirschhorn syndrome phenotype. Am J Med Genet 1999:82:371-75.

20 Medina M, Marinescu RC, Overhauser J, Kosik KS. Hemizygosity of deltacatenin (CTNND2) is associated with severe mental retardation in cri-du-chat syndrome. Genomics 2000;63:157-64.

21 Mehta L, Duckett DP, Young ID. Behaviour disorder in monosomy 10qter. J Med Genet 1987; 24:185-6.

22 de Vries BB, White SM, Knight SJ, Regan R, Homfray T, Young ID, Super M, McKeown C, Splitt M, Quarrell OW, Trainer AH, Niermeijer MF, Malcolm S, Flint J, Hurst JA, Winter RM. Clinical studies on submicroscopic subtelomeric rearrangements: a checklist. J Med Genet 2001;38:145-50.

23 Giglio S, Broman KW, Matsumoto N, Calvari V, Gimelli G, Neumann T, Ohashi H, Voullaire L, Larizza D, Giorda R, Weber JL, Ledbetter DH, Zuffardi $O$. Olfactory receptor-gene clusters, genomic-inversion polymorphisms, and common chromosome rearrangements. Am J Hum Genet $2001 ; 68: 874-83$

24 Sugawara H, Harada N, Ida T, Ishida T, Ledbetter DH, Yoshiura K, Ohta T Kishino T, Niikawa N, Matsumoto N. Complex low copy repeats associated with common polymorphic inversion at human chromosome 8 p23. Genomics 2003:82:238-44

25 Giglio S, Calvari V, Gregato G, Gimelli G, Camanini S, Giorda R, Ragusa A Guerneri S, Selicorni A, Stumm M, Tonnies H, Ventura M, Zollino M, Neri G, Barber J, Wieczorek D, Rocchi M, Zuffardi O. Heterozygous submicroscopic inversions involving olfactory receptor-gene clusters mediated the recurrent t(4;8)(p16;p23) translocation. Am J Hum Genet 2002;71:276-85.

26 Tranebjaerg L, Petersen A, Hove K, Rehder H, Mikkelsen M. Clinical and cytogenetic studies in a large $(4 ; 8)$ translocation family with pre- and postnatal Wolf syndrome. Ann Genet 1984;27:224-9.

27 Tonnies H, Stumm M, Neumann L, Volleth M, Grumpelt U, Musebeck J, Annuss $G$, Neitzel $H$. Two further cases of WHS with unbalanced de novo translocation $\mathrm{t}(4 ; 8)$ characterized by $\mathrm{CGH}$ and FISH. J Med Genet 2001;38:e21

28 Wieczorek D, Krause M, Majewski F, Albrecht B, Meinecke P, Riess O, Gillessen-kaesbach $G$. Unexpected high frequency of de novo unbalanced translocation in patients with Wolf-Hirschhorn syndrome (WHS). J Med Genet 2000;37:798-804 